\title{
NEW OPPORTUNITIES AND CHALLENGES FOR TELEAUDIOLOGY WITHIN DEPARTMENT OF VETERANS AFFAIRS
}

\author{
Peter G. Jacobs, PhD; Gabrielle H. Saunders, PhD
}

\section{INTRODUCTION}

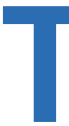
eleaudiology is the delivery of audiology services and information via telecommunications technologies. In recent years, technological advances have resulted in a dramatic increase in the possibilities offered by teleaudiology-from diagnostic audiology and remote hearing aid fittings to downloadable hearing aid applications and real-time rehabilitation interventions. Teleaudiology has the capacity to provide access to audiological services to individuals living in rural locations, to those in inner urban populations who cannot afford or access the services of a professional, and to others who choose to self-manage their hearing impairment. With broader access and new models of service delivery come vast possibilities but also new challenges and questions for patients and professionals alike.

Teleaudiology can be conducted using at least four models of telemedicine practice:

1.Synchronous/real-time data collection, referred to by the Department of Veterans Affairs (VA) as clinical video telehealth, in which face-to-face video-conferencing between patients and providers takes place. Synchronous/real-time data collection can be used to conduct hearing tests, hearing aid fittings, and audiologist-directed real-ear measures, and for hearing-aid counseling and tinnitus management.

2. Store and forward telehealth, in which data are acquired and stored by a technician at a remote facility and later forwarded to a specialist for interpretation and diagnosis. This form of telemedicine can be used to interpret video otoscopy, audiometry, immittence, otoacousticemissions, andauditorybrainstem response readings.

3. Remote monitoring, referred to by VA as home telehealth, in which mobile devices are used to collect data that can be monitored by healthcare providers. Remote monitoring can be used to monitor hearing aid use or changes in hearing over time.

4. Mobile health, in which smartphone applications (apps) or other software is used for self-management of health conditions independent of a practitioner. Mobile health apps for hearing testing, auditory training, tinnitus management, and hearing aid counseling are readily available, as are apps that can turn a smartphone into a sophisticated amplification device. Without question, teleaudiology has effectively overcome barriers such as distance, cost, and the lack of specialist providers in remote locations, to increase access to audiological services. Data from the World Health Organization (WHO) illustrate this considerable need. According to WHO, there are almost 300 million people with moderate-to-profound hearing loss, but of these only about $10 \%$ use any form of hearing assistive technology. This number drops to 2.5 percent for developing countries [1]. Several countries have well-established teleaudiology programs, including Brazil, South Africa, and Australia. In the United States, teleaudiology services are becoming available through programs implemented by the VA and other organizations, such as the Alaska Federal Health Care Access Network (AFHCAN). These programs are driven by need. An estimated 37 percent of enrolled Veterans live in rural areas and 2 percent live in highly rural areas, ${ }^{*}$ with 47 percent of rural and 95 percent of highly rural Veterans living 2 or more hours travel time from a VA clinic [2]. Likewise, 75 percent of Alaskan communities are unconnected by road to a hospital, 25 percent of communities have no airport, and 59 percent of the Alaskan population live in medically underserved areas. Furthermore, 60 percent of the state's physicians live and practice in Anchorage, while only $\mathbf{4 0}$ percent of the population resides

*VHA Planning Systems Support Group, field unit for the VHA Office of Assistant Deputy Under Secretary for Health for Policy \& Planning. Internal document. 2007 Apr 6. Available from: http://www. ruralhealthweb.org/index.cfm?objectid=339169F73048-651A-FE6E4C46248DBF00 
there, with many locations having few or no specialist practitioners [3].

\section{VA TELEAUDIOLOGY}

The VA teleaudiology pilot program began in 2009 as a joint effort between VA Telehealth Services, Office of Rehabilitation Services, and the Audiology and Speech Pathology National Program Office. The initial phase of the project examined the feasibility of remote hearing aid programming at 10 rural Community Based Outpatient Clinics. The feasibility of remote hearing aid programming has been established and will be implemented nationwide. Data from 1,170 have shown patient outcomes with remote hearing aid programming to be as good as or better than those from traditional face-to-face encounters [4]. Other projects examining remote audiometry, home-based teleaudiology, and home-based telerehabilitation are being gradually implemented. In ongoing VA audiology innovation initiatives, the Tennessee Valley VA Healthcare System is working with Audiology Inc to enable automated audiometry, incorporating clinical video, store-and-forward, and home telehealth components into its program. The Greater Los Angeles VA Healthcare System has developed a program called RemotEAR in collaboration with Otovation to utilize a video telehealth hub to deliver hearing healthcare. The VA Puget Sound Health Care System is delivering patient-centered cochlear implant programming through a semiautomated remote programming software package developed by Cochlear Americas, and the Louis Stokes Cleveland VA Medical Center is working with Phonak to evaluate the feasibility of programming hearing aids using novel mobile distant hearing aid fitting software on Veterans' smartphones. It is clear that VA is a leader in teleaudiology in the United States.

Another telehealth success story in the United States is the AFHCAN, managed by Alaska Native Tribal Health Consortium, of which teleaudiology is just one component. The AFHCAN system enables video otoscopy, audiometry, tympanometry, hearing aid clearance, and follow-up to surgery at remote clinics throughout rural Alaska. It is primarily a store-and-forward telehealth system that has been shown to significantly reduce travel costs and improve patient care and satisfaction for patients in rural locations. For example, in 2012 alone, it is estimated that the AFHCAN saved 2.8 million miles of patient travel, yielding an estimated savings of $\$ 8.3$ million. Since the program's inception in 2003, it is estimated that the program has saved $\mathbf{1 2 . 7}$ million travel miles and $\$ 37.8$ million. Furthermore, wait times have been substantially reduced through the implementation of the AFHCAN program with the percentage of appointment wait times longer than 5 mo decreasing from 47 percent prior to implementation of the telehealth program to 3 percent after implementation. Importantly, almost 100 percent of patients surveyed reported they were satisfied with the telemedicine technology, that they would be willing to have a follow-up exam using the same technology, and that the technology was very good at helping them understand their medical problem. Likewise, the vast majority of remote providers agreed that the telehealth program helped improve communication with the doctor, improved the quality of care, improved patient satisfaction, and played an important role in educating the patients about the medical procedures that they underwent [5].

\section{TELEAUDIOLOGY RESEARCH AT NATIONAL CENTER FOR REHABILITATIVE AUDITORY RESEARCH}

At the National Center for Rehabilitative Auditory Research (NCRAR), several new teleaudiology technologies and services are being developed. These include a system to monitor changes in hearing caused by ototoxic drugs, a telephone-based tinnitus education program, and an online hearing conservation program targeting Veterans and the military. The hearing monitoring system, known as the OtolD (Figure), is a take-home system that enables patients to self-administer high-frequency hearing tests at home and compare results with a baseline hearing status acquired prior to the administration of chemotherapeutic drugs. The results are sent wirelessly to a provider who monitors them for changes in highfrequency hearing sensitivity. If changes are seen, the healthcare provider can adjust the chemotherapeutic regimen in the hopes of preventing hearing loss at lower frequencies required for speech understanding. New features are being built into the OtoID that include the use of otoacoustic emissions and prediction algorithms for inferring ototoxic risk $[6,7]$.

The telephone-based tinnitus education program has been developed for Veterans and military personnel with highly disturbing tinnitus. Progressive Tinnitus Management (PTM)-an NCRAR tinnitus management program that has been endorsed by VA Central Officesis conducted via the telephone on multiple occasions. The program, conducted by an audiologist on half of 


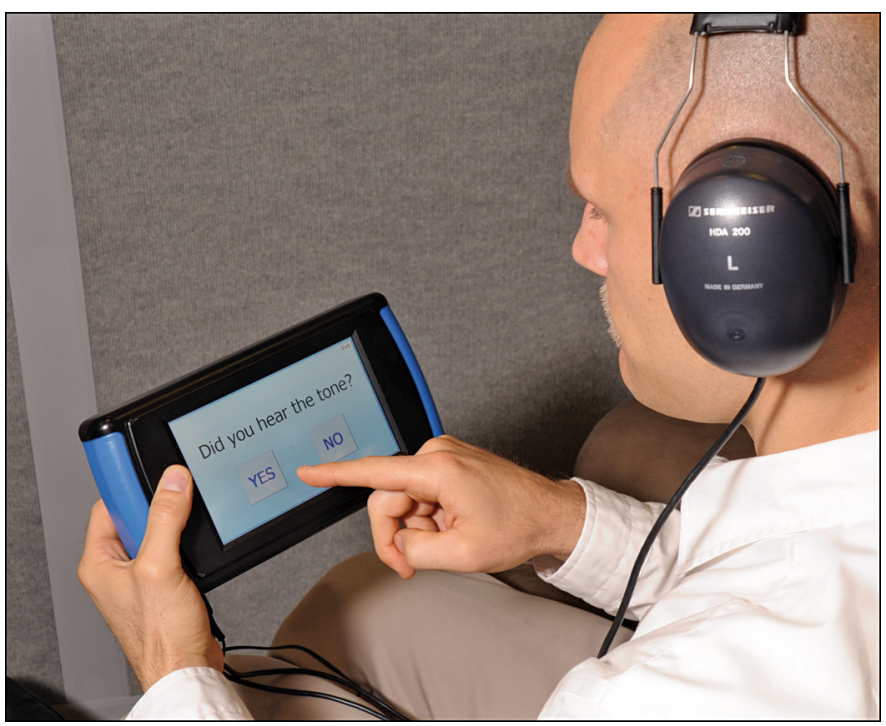

Figure.

Test subject evaluating his hearing using the OtolD system. Reproduced with permission from Jacobs et al. [6].

the occasions and by a psychologist on the other occasions, teaches the patient methods for coping with tinnitus and managing reactions to tinnitus. The program provides easier access to specialists than traditional face-to-face PTM appointments can offer, and, unlike traditional group PTM, it provides one-on-one interactions between patients and providers.

The NCRAR Hearing Loss Prevention Program $[8,9]$ is a self-administered, multimedia, computer-based program with 10 modules that address various aspects of hearing, hearing loss, and hearing conservation through videos, interactive screens, and simulations. It also permits the user to screen his or her hearing and to conduct a self-assessment of the fit of hearing protection devices. The research team is in the process of converting the current stand-alone computerbased format into a Web-based platform, which will greatly increase its accessibility for Veterans and servicemembers and will allow greater customization of content for Veterans, as well as Army, Navy, and Air Force personnel.

\section{TRENDS CONTRIBUTING TO GROWTH IN TELEAUDIOLOGY}

Cellular telephones provide an excellent forum for provision of teleaudiological services and, fortuitously, access to this technology is rapidly increasing. Indeed, according to a report from the World Bank, 75 percent of the world's population now has access to a cellular telephone [10]. Even in regions such as Africa, where there is little to no provision of hearing healthcare [11], there are about 700 million active cellular telephones for the 1 billion who live there [10]. Although currently many of these cellular telephones cannot access the Internet, it is predicted that in countries such as South Africa smartphones with Internet access will begin to dominate the cellular telephone market by 2017 [12].

Video conferencing is now common for many people living within the United States as friends and relatives keep in touch using such technologies as Apple's FaceTime or Microsoft's Skype. These services are available on mobile telephones as well as computers, making it possible to implement clinical video telehealth using off-the-shelf mobile telephones and tablets. The high resolution cameras available on smartphones and computer tablets put the power of store-and-forward technology into the hands of consumers. Furthermore, in-home remote sensors such as infrared sensors, video surveillance cameras, and medication monitoring sensors are bringing home telehealth services into the mainstream and are making these technologies available as consumer products independent of practitioners.

In addition to the availability of mobile telephones and Internet connectivity, low-cost hearing assistive devices, known as personal sound amplification products (PSAPs), are becoming available through nontraditional channels such as online retailers. While PSAPs are controversial and arguably lower quality than those that can be provided by a skilled audiologist, the reduced cost and widespread availability make it easier and more affordable for people to integrate such devices into their lives. The long-term benefit of such systems to the user and their impact on the field of audiology remains to be seen.

\section{OPPORTUNITY FOR AUDIOLOGISTS AND OTHER HEALTHCARE PROVIDERS}

Audiologists should avail themselves of the opportunity to use cellular telephone technology and other sophisticated telecommunication systems to provide remote hearing healthcare services to individuals in rural America and other areas of the world where physical access to a provider is difficult. Smartphones have the capacity to be used as amplifiers or hearing assistive 
devices because they can generate high fidelity acoustic signals that can be delivered via earphones or loud speakers to a listener. They can also be used for otoscopy because they have high-quality video cameras, and for remotely controlling devices such as audiometers, tympanometers, and hearing aids. Some smartphones even have multiple microphones and thus can apply sophisticated signal processing algorithms such as adaptive beamforming, which can be used for hearing aid noise cancellation, and most can stream acoustic data wirelessly via a telecoil or a Bluetooth interface, permitting interpretation of data remotely.

Indeed, a number of hearing-related smartphone applications already exist. There are apps for testing and screening hearing sensitivity, apps that use sound equalizers to shape and amplify signal output, programs that simulate hearing loss so that users can better understand hearing loss, and others that enable the cellular telephone to be used as a visual and tactile alerting device.

However, clinicians and patients must be willing to accept teleaudiology as a form of practice if its use is to become mainstream. Work to date suggests that clinicians are open to using teleaudiology for answering patients' questions and for counseling; clinicians are moderately accepting of remote hearing aid adjustment and hearing screening but have reservations about using teleaudiology for hearing aid fittings and assessments, especially for new hearing aid users [13]. The patient perspective is somewhat more positive, with about 75 percent of patients being moderately to extremely willing to try teleaudiology. Further, twothirds of clinicians and patients in a small industryfunded study became more positive about the use of teleaudiology after having engaged in its use [13].

\section{ENVISIONING A SYSTEM OF THE FUTURE}

It is not difficult to envisage a teleaudiology system of the future in which a smartphone is used for audiometric diagnostics, hearing aid programming and fine-tuning, and controlling hearing aid output using adaptive programming that can change based upon a specific location or listening environment. Such a system could link audiologists with patients located across the world via secure websites that store audiometric and hearing aid fitting data. Whether low cost distribution methods for delivering hearing aid hardware are used or whether the smartphone itself is used as the hearing aid, such systems could be imminently realizable. As discussed by Jacobs \& Saunders [14], "the combination of smart phone technology and sophisticated networked apps could enable audiology to be performed in a minimally equipped remote clinic, as follows:

- Licensed audiologists in the U.S. would train technicians located in remote communities to carry out standard diagnostic and hearing fitting procedures using interactive video conferencing software. These technicians would work part-time in the community medical clinic.

-When someone at the clinic reported hearing difficulties, the technician would use a smart phone app to test the person's hearing and to make a video recording of the otoscopic exam. These data would be sent over the phone directly to the U.S.based audiologist, who would determine what intervention was needed. If warranted, a low-cost hearing aid, perhaps in the form of a kit similar to that described by Convery et al. [15], would be fitted and adjusted by the technician via a USB interface with the technician's cell phone. The patient would then be instructed by the technician on hearing aid use and upkeep.

- In addition, an app would be downloaded onto the patient's phone. It would provide general hearing aid information and could also be used to improve hearing aid performance by enabling advanced multi-microphone adaptive beamforming and other noise-cancellation algorithms.

- Payment for the service would go primarily to the technician. However, the U.S.-based audiologists would receive compensation for training technicians and for their participation, or alternatively they could receive a charity tax deduction for their time" [14].

The infrastructure for the system above is already largely available. However, for such a teleaudiology system to become a reality, further work must be done to ensure patient privacy of personal health information, there must be a system for between state/country licensing of professionals, and viable methods for reimbursement of hearing health care providers must be developed, as must training programs for technicians and other providers. Finally, users of downloadable apps need mechanisms to evaluate the validity of the results they provide. While it can be argued that awareness of hearing loss can be raised among the general public through easy access to hearing testing and amplification, it may be detrimental if individuals 
with hearing loss receive feedback from an app that their hearing is normal, or they use suboptimal amplification for long periods of time. While strict regulation of apps is clearly undesirable, information on validity and reliability is appropriate.

Peter G. Jacobs, PhD; ${ }^{1-2 *}$ Gabrielle H. Saunders, PhD² ${ }^{1}$ Department of Biomedical Engineering, Oregon Health \& Science University, Portland, OR; ${ }^{2}$ National Center for Rehabilitative Auditory Research, Portland Department of Veterans Affairs Medical Center, Portland, OR

*Email: jacobsp@ohsu.edu

\section{REFERENCES}

1. World Health Organization Fact Sheet [Internet]. Washington (DC): WHO; 2014. Available from: http://www. who.int/mediacentre/factsheets/fs300/en/index. html

2. West AN, Lee RE, Shambaugh-Miller MD, Bair BD, Mueller KJ, Lilly RS, Kaboli PJ, Hawthorne K. Defining "rural" for veterans' health care planning. J Rural Health. 2010;26(4):301-9. [PMID:21029164] http://dx.doi.org/10.1111/j.1748-0361.2010.00298.x

3. Alaska Physician Supply Task Force report [Internet]. Juneau (AK): Alaska Department of Health and Social Services; 2006. Available from http://dhss.alaska.gov/ Commissioner/Pages/PhysicianSupply.aspx

4. Gladden C. The current status of VA audiology. Proceedings of the 6th Biennial NCRAR Conference Beyond the Clinic: Innovations and Possibilities of Connected Health; 2013 Sep 18-20; Portland, OR.

5. Kokesh J, Ferguson S. Outcomes and impacts of the AFHCAN telehealth program treating ear and hearing disease in Alaska. Proceedings of the 6th Biennial NCRAR Conference Beyond the Clinic: Innovations and Possibilities of Connected Health; 2013 Sep 18-20; Portland, OR.

6. Jacobs PG, Silaski G, Wilmington D, Gordon S, Helt W, McMillan G, Fausti SA, Dille M. Development and evaluation of a portable audiometer for high-frequency screening of hearing loss from ototoxicity in homes/clinics. IEEE Trans Biomed Eng. 2012;59(11):3097-3103. [PMID:22801480] http://dx.doi.org/10.1109/TBME.2012.2204881

7. Dille MF, Jacobs PG, Gordon SY, Helt WJ, McMillan GP. OtolD: New extended frequency, portable audiometer for ototoxicity monitoring. J Rehabil Res Dev. 2013; 50(7):997-1006. [PMID:24301436]

http://dx.doi.org/10.1682/JRRD.2012.09.0176

8. Folmer RL, Saunders GH, Dann SM, Griest SE, Porsov E, Fausti SA, Leek MR. Guest editorial: Computer-based hearing loss prevention education program for Veter- ans and military personnel. J Rehabil Res Dev. 2012; 49(4):vii-xvi. [PMID:22773265]

http://dx.doi.org/10.1682/JRRD.2012.02.0028

9. Saunders GH, Griest SE. Hearing loss in veterans and the need for hearing loss prevention programs. Noise Health. 2009;11(42):14-21. [PMID:19265249] http://dx.doi.org/10.4103/1463-1741.45308

10. World Bank. Information and communications for development 2012: Maximizing mobile [Internet] Washington (DC): World Bank; 2012. Available from: http://www.worldbank.org/ict/IC4D2012

11. Swanepoel W, Olusanya BO, Mars M. Hearing healthcare delivery in sub-Saharan Africa-a role for teleaudiology. J Telemed Telecare. 2010;16(2):53-56. [PMID:20008052]

http://dx.doi.org/10.1258/jtt.2009.009003

12. Groupe Speciale Mobile Association., Sub-Saharan Africa mobile observatory 2012 [Internet]. London (UK): GSMA; 2012. Available from: http://www.gsma.com/ publicpolicy/wp-content/uploads/2012/03/gsma ssamo_full_web_11_12.pdf

13. Singh G, Pichora-Fuller MK, Malkowski M, Boretzki M, Launer S. A survey of the attitudes of practitioners toward teleaudiology. Int J Audiol. 2014;14:1-11. [PMID:25017424]

14. Jacobs PG, Saunders GH. Leveraging smart phone technology to realize a system of teleaudiology [Internet]. Hearing Health and Technology Matters; 2013. Available from: http://hearinghealthmatters.org/ hearingviews/2013/leveraging-smart-phonetechnology-to-realize-a-system-of-teleaudiology

15. Convery E, Keidser G, Dillon H, Hartley L. A self-fitting hearing aid: Need and concept. Trends Amplif. 2011;15(4):157-66. [PMID:22143873] http://dx.doi.org/10.1177/1084713811427707

This article and any supplementary material should be cited as follows:

Jacobs PG, Saunders GH. New opportunities and challenges for teleaudiology within Department of Veterans Affairs. J Rehabil Res Dev. 2014;51(5):vii-xii. http://dx.doi.org/10.1682/JRRD.2014.04.0093

ResearcherID/ORCID: Peter G. Jacobs, PhD: I-52362014; Gabrielle H. Saunders, PhD: F-4768-2012

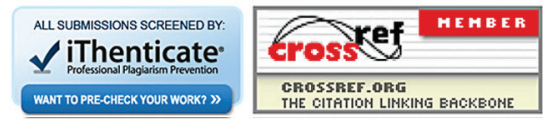

